\title{
Colonoscopy Use in a Country with a Long-Standing Colorectal Cancer Screening Programme: Evidence from a Large German Survey
}

\author{
Inanspruchnahme der Koloskopie in einem Land mit langjähriger Darmkrebs- \\ vorsorge: Ergebnisse eines großen Surveys in Deutschland
}

Authors
Affiliations
Schlüsselwörter
Inanspruchnahme der
Koloskopie
Darmkrebs
Survey
Deutschland
Key words
colonoscopy use
survey
colorectal cancer
Germany

received $\quad 11.4 .2010$

accepted $\quad 9.7 .2010$

Bibliography

Dol http://dx.doi.org/10.1055/

s-0029-1245611

Z Gastroenterol 2010; 48:

1351-1357 @ Georg Thieme

Verlag KG Stuttgart · New York ISSN 0044-2771

\section{Correspondence}

\section{Prof. Dr. Monika Sieverding}

Psychologisches Institut,

Ruprecht-Karls-Universität

Heidelberg

Hauptstr. $47-51$

69117 Heidelberg

Germany

Tel.: ++49/6221/547372

Fax: $++49 / 6221 / 547325$

monika.sieverding@

psychologie.uni-heidelberg.de
M. Sieverding ${ }^{1}$, U. Matterne ${ }^{2}$, L. Ciccarello ${ }^{3}$, U. Haug ${ }^{4}$

Department of Psychology, University of Heidelberg, Heidelberg, Germany

2 Clinical Social Medicine, University Hospital Heidelberg, Heidelberg, Germany

3 Department of Psychology, University of Mannheim, Mannheim, Germany

${ }^{4}$ Division of Clinical Epidemiology and Aging Research, German Cancer Research Center, Heidelberg, Germany

\section{Zusammenfassung \\ $\nabla$}

Hintergrund: Angesichts des Potenzials der Koloskopie hinsichtlich Prävention und Früherkennung von Darmkrebs ist deren bevölkerungsweite Inanspruchnahme ein wichtiger Parameter, um die zukünftige Krankheitslast abzuschätzen. Ziel der Studie war es, die insgesamte Prävalenz und die Determinanten koloskopischer Untersuchungen in Deutschland zu untersuchen, einem Land mit langjähriger Darmkrebsvorsorge.

Methodik: Die Daten wurden im Jahr 2004 im Rahmen des Health Care Access Panels, einer bundesweit repräsentativen Befragung deutscher Haushalte, erhoben. Die Stichprobe umfasste 15810 Männer und Frauen im Alter zwischen 50 und 70 Jahren, ohne Krebsvorgeschichte.

Ergebnisse: Insgesamt gaben 36\% der Befragten an, dass sie in der Vergangenheit mindestens einmal koloskopisch untersucht wurden $25 \%$ einmalig und $11 \%$ mehr als einmal). Die Prävalenz koloskopischer Untersuchungen stieg mit dem Alter steil an (von 25\% in der Altergruppe $50-54$ bis zu $43 \%$ in der Altersgruppe $65-70$ ) und unterschied sich kaum zwischen Frauen und Männern. Die frühere Durchführung eines Tests auf Blut im Stuhl war bei beiden Geschlechtern das wichtigste Korrelat einer koloskopischen Untersuchung.

Schlussfolgerung: Nach unserem Survey aus dem Jahr 2004 wurde bei mehr als einem Drittel der deutschen Bevölkerung bis zum 70. Lebensjahr mindestens einmal eine Koloskopie durchgeführt. Zum Zeitpunkt der Befragung war der Test auf Blut noch das gebräuchlichste Verfahren in der Darmkrebsvorsorge. Längerfristig ist davon auszugehen, dass die Früherkennungs-Koloskopie zu Veränderungen in der Inanspruchnahme der Koloskopie führen wird. Die Ergebnisse dieses Surveys können als Bezugspunkt dienen, um entsprechende Veränderungen zu charakterisieren und zu quantifizieren.

\section{Abstract \\ V}

Background: Given the potential colonoscopy has in prevention and early detection of colorectal cancer (CRC), its overall use within a population is a meaningful parameter to estimate the future CRC burden. We aimed to examine overall prevalence and correlates of colonoscopy use in Germany, a country with a long-standing, opportunistic CRC screening programme.

Methods: The data were collected in 2004 through the Health Care Access Panel, a nationally generalisable survey of German households. The sample comprised 15,810 men and women aged 50 to 70 years without a personal history of cancer.

Results: Overall, $36 \%$ of respondents reported to have had at least one colonoscopy in the past ( $25 \%$ once and $11 \%$ more than once). Prevalence of colonoscopy use strongly increased by age (from $25 \%$ to $43 \%$ in age groups $50-54$ and 65 70 , respectively), but hardly differed by sex. Previous faecal occult blood testing (FOBT) was the most important correlate of colonoscopy use in either sex.

Conclusions: Our survey from 2004, when FOBT was still the most important screening tool in Germany, suggests that more than one third of the German population underwent colonoscopy at least once up to age 70 . While introduction of screening colonoscopy is expected to impact on overall colonoscopy use in the long run, these data can serve as point of reference to assess the extent and the patterns of such changes. 


\section{Introduction}

$\nabla$

Colorectal cancer (CRC) is among the most common cancers worldwide, with incidence rates being particularly high in industrialised countries [1]. The preventive potential colonoscopies, by allowing the removal of precursor lesions, has been increasingly recognised. Recent observational studies have shown a strong inverse association between the risk of developing CRC and (ever) use of colonoscopy (irrespective of indication) [2-5]. Thus, the overall colonoscopy use of a population may become a meaningful parameter to estimate future CRC burden. Apart from this public health relevance, overall colonoscopy use is an important parameter in terms of estimating colonoscopy-related health care costs and required capacities.

Overall colonoscopy use in the general population is difficult to estimate because there are different reasons that could lead to colonoscopy, such as gastrointestinal symptoms or CRC screening (e.g., a follow-up colonoscopy after a positive FOBT). Furthermore, it is expected that there is a certain overlap between colonoscopies (formally) performed in the context of CRC screening and colonoscopies performed due to symptoms. Population-based health surveys are therefore an important tool to estimate the overall colonoscopy use in the general population. While such survey data are abundantly available for the U.S. population collected within national health surveys on a regular basis (Behavioral Risk Factor Surveillance System, National Health Interview Survey), corresponding estimates are extremely scarce for European countries [6].

In Germany, a population-based CRC screening programme with annual FOBT and colonoscopic follow-up of positive test results has been offered since 1977 to individuals from age 50. While FOBT screening continues to be offered, screening colonoscopy was introduced in late 2002 as an alternative to FOBT screening from age 55. Participation rates in screening colonoscopy, which are documented in detail (stratified by age, sex and year) within a national screening colonoscopy database are low [7]. Generally, there is no organised structure of inviting or reminding individuals to participate in colorectal cancer screening, i.e., it is an opportunistic screening programme. All screening-related costs are covered by the mandatory health insurance.

The aim of this study was to assess the overall colonoscopy use in Germany in 2004, a country where an opportunistic CRC screening programme has been in place for more than 30 years, by means of a large, nationally representative survey.

\section{Participants and Methods \\ $\nabla$}

\section{Study population and setting}

The data for this study were collected within the Health Care Access Panel (HCAP) of the year 2004. The HCAP, which was first carried out in 1999, is a large German household panel survey which was developed as a multi-purpose database providing information about chronic diseases and health-care utilisation in the general population. It uses a sampling method specifically designed to arrive at representative population samples. Furthermore, individual weighting factors are calculated to account for slight deviations from the general population with respect to age, sex and region. The validity of data provided by the HCAP in terms of its representativeness has been carefully checked and confirmed by comparison with national data sources provided by the German Federal Office for Statistics and previous health surveys $[8,9]$. The HCAP of the year 2004 contained 71,446 persons aged 20-70 years and the household response rate was $58 \%$. For the present study only respondents $\geq 50$ years were included $(n=17,146)$. 1,336 persons with a personal history of cancer were excluded from the study. The final sample for the present study comprised 15,810 adults aged $50-70$ years.

\section{Data collection}

Data collection took place between August and October 2004 by mailed questionnaires. Due to delayed data processing and prioritising of other research questions, we analysed the data regarding colonoscopy use only in 2009. The development of the questionnaire included piloting and pre-testing of the items in independent samples to ensure its clarity and comprehension.

Participants were asked if they had undergone colonoscopy in the past (assessed by the German colloquial term 'Darmspiegelung' for colonoscopy) with the possible answers "never", "once" and "more than once". In addition, we assessed potential correlates of colonoscopy use: Information on past adherence to FOBT screening (possible answers "never", "irregularly", "regularly every 1-2 years"), and sociodemographic data including age in years, marital status, family size, education ( $9^{\text {th }}$ grade or under, $10^{\text {th }}$ grade, high school certificate, college graduate), monthly family income and health insurance status (public versus private) were collected. Family history of cancer was assessed by asking the participants whether they had knowledge of (any) cancer amongst their grandparents, parents or siblings ("no"; "yes, one person"; "yes, two or more persons"). Physician's recommendation was assessed by asking participants whether a physician had recommended that they undergo a test for the early detection of cancer ( $1=$ yes, $0=$ no/ I don't know). General medical check-up was measured by asking participants to indicate on a four-point scale ("never", "irregularly", "every two years" or "annually") whether and how regularly they had attended a free medical check-up as provided by the German health-care system starting at age 35 .

\section{Statistical analysis}

The study population was described with respect to age, sociodemographic variables, physician's recommendation for cancer screening and utilisation of preventive health-care; sex differences were assessed using chi square statistics. Colonoscopy use was first assessed on a three-point scale according to the original answers ("never", "once", "more than once"). In the following analyses the three-point variable was dichotomised into "ever colonoscopy use" (i.e., at least one colonoscopy) and "never colonoscopy use". The prevalence of "ever colonoscopy use" was stratified by age and sex. We further estimated the prevalence of "ever colonoscopy use" stratified by age and sex for the scenario that screening colonoscopy would not have been offered. The latter estimate was derived from the annual adherence to screening colonoscopy since its introduction, i.e., two years before this survey was conducted (ranging from $2-5 \%$, see Supplementary Table in Appednix) and taking into account that a certain proportion of people participating in screening colonoscopy had another colonoscopy before (see Appendix for the formulae and parameters used to compute these estimates). 


\begin{tabular}{|c|c|c|c|c|}
\hline & & men $(n=7735)$ & women $(n=8075)$ & p value \\
\hline \multicolumn{2}{|l|}{ variable $^{1}$} & n (\%) & $n(\%)$ & \\
\hline \multirow[t]{5}{*}{ age (years) } & & & & $<0.01$ \\
\hline & $50-54$ & $2439(31.5)$ & $2761(34.2)$ & \\
\hline & $55-59$ & $2066(26.7)$ & $2027(25.1)$ & \\
\hline & $60-64$ & $1938(25.1)$ & $1950(24.1)$ & \\
\hline & $65-70$ & $1292(16.7)$ & $1337(16.6)$ & \\
\hline \multirow[t]{3}{*}{ marital status } & & & & $<0.001$ \\
\hline & married & $6414(83.0)$ & $5589(69.2)$ & \\
\hline & single/separated/divorced/widowed & $1316(17.0)$ & $2484(30.8)$ & \\
\hline \multirow[t]{6}{*}{ family size } & & & & $<0.001$ \\
\hline & 1 & $867(11.2)$ & $16860(20.9)$ & \\
\hline & 2 & $3997(51.7)$ & $4341(53.8)$ & \\
\hline & 3 & $1563(20.2)$ & $1341(16.6)$ & \\
\hline & 4 & $950(12.3)$ & $531(6.6)$ & \\
\hline & $\geq 5$ & $358(4.6)$ & $176(2.2)$ & \\
\hline \multirow[t]{5}{*}{ education } & & & & $<0.001$ \\
\hline & $9^{\text {th }}$ grade or under & $3655(48.7)$ & $3926(49.6)$ & \\
\hline & $10^{\text {th }}$ grade & $1825(24.3)$ & $2635(33.3)$ & \\
\hline & High school graduation & $591(7.9)$ & $499(6.3)$ & \\
\hline & College graduation & $1435(19.1)$ & $849(10.7)$ & \\
\hline \multicolumn{2}{|c|}{ family income per month } & & & $<0.001$ \\
\hline & $<1,750 €$ & $2409(33.1)$ & $3425(45.1)$ & \\
\hline & $1750 €-2749 €$ & $2578(35.4)$ & $2387(31.4)$ & \\
\hline & $\geq 2750 €$ & $2296(31.5)$ & $1781(23.5)$ & \\
\hline \multicolumn{2}{|c|}{ health insurance } & & & $<0.001$ \\
\hline & public & $6563(86.0)$ & $7418(92.5)$ & \\
\hline & private & $1068(14.0)$ & $601(7.5)$ & \\
\hline \multicolumn{2}{|c|}{ family cancer history } & & & $<0.001$ \\
\hline & no & $4646(60.9)$ & $4170(52.1)$ & \\
\hline & yes: 1 person & $2282(29.9)$ & $2605(32.6)$ & \\
\hline & yes: $\geq 2$ persons & $705 \quad(9.2)$ & $1225(15.3)$ & \\
\hline \multicolumn{2}{|c|}{ physician's recommendation (cancer screening) } & & & $<0.001$ \\
\hline & no & $3519(46.4)$ & $2683(33.9)$ & \\
\hline & yes & $4064(53.6)$ & $5230(66.1)$ & \\
\hline \multicolumn{2}{|c|}{ medical check-up } & & & $<0.001$ \\
\hline & never & $1957(25.6)$ & $1133(14.2)$ & \\
\hline & irregularly & $2160(28.2)$ & $1918(24.0)$ & \\
\hline & every two years & $1609(21.0)$ & $1779(22.3)$ & \\
\hline & every year & $1927(25.2)$ & $3154(39.5)$ & \\
\hline \multirow[t]{4}{*}{ FOBT } & & & & $<0.0001$ \\
\hline & never & $2323(31.2)$ & $1393(17.9)$ & \\
\hline & irregularly & $1854(24.9)$ & $1530(19.6)$ & \\
\hline & regularly every $1-2$ years & $3281(44.0)$ & $4869(62.5)$ & \\
\hline
\end{tabular}

${ }^{1} \mathrm{~N}$ for each variable varies slightly due to missing data, which varied from $0-5.9 \%$.

To examine correlates of life-time colonoscopy use (using the dichotomised variable "ever colonoscopy use" as described above) we performed multivariable logistic hierarchical regression analyses taking into account potential clustering within the data. The analyses were done stratified by sex analogously to previous analyses of the survey data regarding correlates of FOBT use [10]. Sociodemographic variables were entered in the first step and all other variables (family history of cancer, use of medical checkups, physician recommendation, FOBT use) in the second step. We used adjusted odds ratios (ORs) and 95\% confidence intervals (CI) to summarise the results of the logistic regressions.

Except for the description of the study population ( Table 1 ), we weighted the variables in all analyses according to the individual weights to optimise representativeness of the results. Statistical analyses were carried out using SPSS for Windows (Version 14).

\section{Results}

$\nabla$

The overall sample of 15,810 participants comprised 7,735 men (48.9\%) and 8,075 women (51.1\%). The mean age was 58 years (men: $58.3, \mathrm{SD}=5.5$; women $58.1, \mathrm{SD}=5.7$ ). Further characteristics of the study population are shown in $\bullet$ Table 1. The distributions of sociodemographic variables mirror the socioeconomic differences between men and women in the general German population (Federal Statistical Office, 2005). Women reported more often a family history of cancer than men. They also reported more frequently to have received a physician's recommendation for cancer screening and to have utilised preventive health-care measures including FOBT screening. 


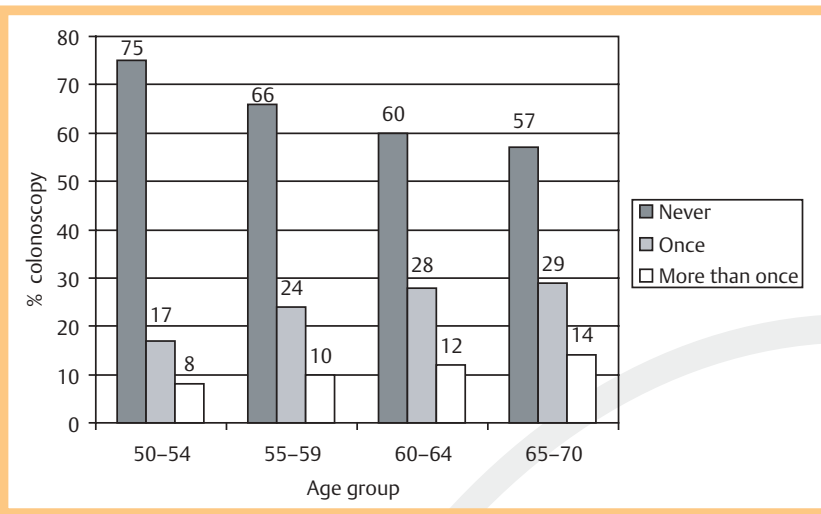

Fig. 1 Prevalence of previous colonoscopy use stratified by age.

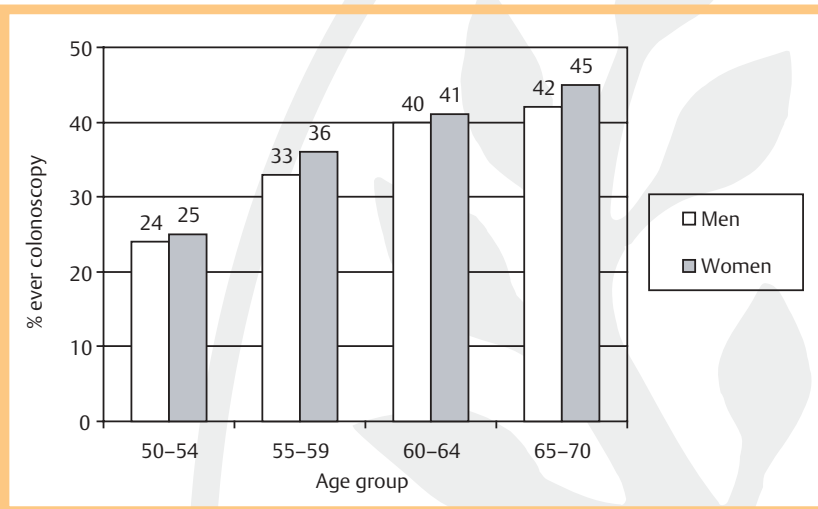

Fig. 2 Lifetime prevalence of colonoscopy use, stratified by age and sex.

\section{Prevalence of colonoscopy use}

Overall, the proportion of participants without previous colonoscopy was $64.4 \%$, while $24.6 \%$ had one colonoscopy and $11.0 \%$ had more than one colonoscopy in the past. The proportion of respondents with "never colonoscopy" was slightly higher in men than in women (66 vs. $63 \%$ ), but this sex difference was marginal in size, although statistically significant $(\mathrm{p}<0.01$, Cramer's $\mathrm{V}=0.04)$. Accordingly, the proportion of respondents reporting "one colonoscopy" was slightly higher in women than in men ( 26 vs. $23 \%$ ), while the proportion reporting "more than one colonoscopy" was the same in both sexes $(11 \%)$. Prevalence of previous colonoscopy use increased with age ( $\mathbf{F i g . 1}$ ). The proportion of participants with one previous colonoscopy increased from $17 \%$ in age group $50-54$ to $29 \%$ in age group $65-70$. The increase with age was less pronounced regarding prevalence of "more than one colonoscopy", which was $8 \%$ in age group $50-54$ and increased to $14 \%$ in age group 65-70.

- Fig. 2 shows lifetime prevalence of colonoscopy use (i.e., one colonoscopy or more) stratified by age and sex. In age group $50-54$ one quarter of both men and women had at least one previous colonoscopy. Lifetime prevalence strongly increased with age and was slightly higher in women than men in all age groups. The highest prevalence of colonoscopy use was observed in women aged $65-70$, amounting to $45 \%$. When estimating life-time prevalence of overall colonoscopy use for the scenario that screening colonoscopy would not have been offered, the proportions decreased by about $6-8 \%$ in the different strata above age 55 . Again the prevalence of colonoscopy use was estimated to be highest in age group $65-70$, amounting to $39 \%$ in women and $35 \%$ in men (see Appendix).

\section{Correlates of colonoscopy use stratified by sex}

As described in the methods section, sociodemographic variables were entered first and followed by the remaining variables in a second step. The explained variance in the models adjusting for sociodemographic variables (including age) was very small (Nagelkerke's $R^{2}=0.01$ for either sex) (data not shown). - Table 2 shows the ORs for the correlates of lifetime colonoscopy use adjusted for all variables and stratified by sex. Several variables showed sex-specific patterns regarding their association with colonoscopy use. Age correlated with previous colonoscopy use in both sexes, but the association was more distinct among women. Family size was inversely associated with colonoscopy use in men but not in women. Income was not associated with colonoscopy use in men, while among women the odds of having had a colonoscopy were statistically higher in the highest compared to the lowest income group. As to education, there was no clear association or trend in both sexes and also the type of health insurance (private versus public) did not correlate with colonoscopy use. Family history of cancer was significantly associated with colonoscopy use both among men and women, but was more pronounced in women. Among men, only those reporting two or more relatives with cancer showed increased ORs. Regular medical check-ups correlated with colonoscopy use in both men and women, but the association was again more pronounced in women. By contrast, physician's recommendation to undergo cancer screening tests was associated with colonoscopy use only in men. Previous FOBT use showed the strongest association with colonoscopy use in both men and women. Adding use of medical check-ups, physician's recommendation, family history of cancer and previous FOBT use led to a marked increase in explained model variance $\left(\Delta\right.$ Nagelkerke's $R^{2}{ }_{\text {men }}=0.24, \Delta$ Nagelkerke's $R^{2}{ }_{\text {women }}=0.17$ ). The increase was higher for men than for women suggesting that these variables are better combined predictors regarding colonoscopy use in men.

\section{Discussion \\ $\nabla$}

This large health survey from 2004 showed that a substantial proportion of the German population between age 50 and 70 had at least one previous colonoscopy. Self-reported lifetime prevalence of colonoscopy use was already $25 \%$ in age group $50-55$, rising to $40 \%$ and more in higher age groups. Adherence to previous FOBT screening, introduced in 1977, was the most important predictor of lifetime colonoscopy use, both in men and in women. About $6-8 \%$ of lifetime colonoscopy use in 2004 was estimated to be attributable to the screening colonoscopy programme which has been introduced in late 2002 and shows comparatively low annual adherence rates. According to a representative cross-sectional survey from 2008, about $42 \%$ of the German population aged 55-69 reported to have ever had a colonoscopy, compared to $40 \%$ in the same age group in our survey from 2004. Even though the survey from 2008 included only 423 subjects in age group $55-69$, the data do not indicate a substantial increase in overall colonoscopy use since 2004, despite the continuous offer of screening colonoscopy [11]. 


\begin{tabular}{|c|c|c|c|c|}
\hline & \multicolumn{2}{|c|}{ men $(n=5258)$} & \multicolumn{2}{|c|}{ women $(n=5263)$} \\
\hline & $\mathrm{OR}^{3}$ & (95\% Cl) & $\mathbf{O R}^{3}$ & $(95 \% \mathrm{Cl})$ \\
\hline \multicolumn{5}{|l|}{ sociodemographic variables } \\
\hline \multicolumn{5}{|l|}{ age } \\
\hline $55-59$ & 1.00 & & 1.00 & \\
\hline $60-64$ & $1.28^{* *}$ & $(1.09-1.51)$ & $1.31^{* * *}$ & $(1.13-1.51)$ \\
\hline $65-70$ & $1.20^{*}$ & $(1.01-1.43)$ & $1.55^{* * *}$ & $(1.33-1.80)$ \\
\hline \multicolumn{5}{|l|}{ marital status } \\
\hline No & 1.00 & & 1.00 & \\
\hline Yes & 1.20 & $(0.90-1.59)$ & 0.93 & $(0.75-1.16)$ \\
\hline \multicolumn{5}{|l|}{ family size } \\
\hline 1 & 1.00 & & 1.00 & \\
\hline 2 & $0.57^{* *}$ & $(0.42-0.79)$ & 0.94 & $(0.74-1.20)$ \\
\hline 3 & $0.60^{* *}$ & $(0.42-0.87)$ & 0.95 & $(0.70-1.29)$ \\
\hline 4 & 0.65 & $(0.41-1.02)$ & 0.81 & $(0.49-1.33)$ \\
\hline more than 4 & $0.49^{*}$ & $(0.27-0.89)$ & 1.67 & $(0.75-3.08)$ \\
\hline \multicolumn{5}{|l|}{ family income per month } \\
\hline$<1750 €$ & 1.00 & & 1.00 & \\
\hline $1750-2749 €$ & 0.98 & $(0.83-1.15)$ & 1.07 & $(0.93-1.24)$ \\
\hline$\geq 2750 €$ & 0.85 & $(0.71-1.03)$ & $1.36^{* *}$ & $(1.13-1.64)$ \\
\hline \multicolumn{5}{|l|}{ education } \\
\hline $9^{\text {th }}$ grade or under & 1.00 & & 1.00 & \\
\hline $10^{\text {th }}$ grade & 1.09 & $(0.91-1.29)$ & 0.98 & $(0.86-1.12)$ \\
\hline High school degree & $1.35^{*}$ & $(1.05-1.74)$ & 0.83 & $(0.64-1.06)$ \\
\hline College degree & 1.16 & $(0.96-1.39)$ & 0.88 & $(0.70-1.08)$ \\
\hline \multicolumn{5}{|l|}{ health insurance } \\
\hline public & 1.00 & & 1.00 & \\
\hline private & 1.04 & $(0.85-1.27)$ & 0.94 & $(0.75-1.20)$ \\
\hline \multicolumn{5}{|l|}{ other variables } \\
\hline \multicolumn{5}{|l|}{ family history of cancer } \\
\hline no & 1.00 & & 1.00 & \\
\hline one family member & 1.06 & $(0.91-1.22)$ & $1.30^{* * *}$ & $(1.14-1.47)$ \\
\hline two or more family members & $1.38^{* *}$ & $(1.11-1.73)$ & $1.60^{* * *}$ & $(1.31-1.85)$ \\
\hline \multicolumn{5}{|l|}{ medical check-up } \\
\hline never & 1.00 & & 1.00 & \\
\hline irregularly & 1.00 & $(0.78-1.28)$ & 1.13 & $(0.90-1.44)$ \\
\hline every two years & 1.16 & $(0.90-1.50)$ & $1.63^{* *}$ & $(1.29-2.05)$ \\
\hline annually & $1.57^{* * *}$ & $(1.22-2.02)$ & $1.88^{* * *}$ & $(1.50-2.34)$ \\
\hline \multicolumn{5}{|c|}{ physician's recommendation (cancer screening) } \\
\hline no & 1.00 & & 1.00 & \\
\hline yes & $1.26^{* *}$ & $(1.09-1.45)$ & 1.08 & $(0.95-1.23)$ \\
\hline \multicolumn{5}{|l|}{ FOBT } \\
\hline never & 1.00 & & 1.00 & \\
\hline irregularly & $8.40^{* * *}$ & $(6.38-11.05)$ & $8.43^{* * *}$ & $(6.30-11.26)$ \\
\hline $\begin{array}{l}\text { regularly every } \\
1-2 \text { years }\end{array}$ & $11.22^{* * *}$ & $(8.49-14.81)$ & $10.41^{* * *}$ & $(7.89-13.74)$ \\
\hline \multicolumn{5}{|c|}{$\begin{array}{l}1 \text { Coding: } 0=\text { no, } 1 \text { = yes. } \\
2 \text { As screening colonoscopy is only offered to people from age } 55 \text { we excluded participants below age } 55 \text { when examining } \\
\text { correlates of life-time colonoscopy use to ensure homogeneity and comparability in this regard. } \\
3 \text { Odds ratios }(O R) \text { are adjusted for all other variables entered: age, marital status, family size, family income, education, } \\
\text { health insurance, family history of cancer, medical checkup, physician's recommendation and FOBT use; text in italics } \\
\text { indicates statistically significant associations for test of difference from respective reference category; significance of } \\
\text { Wald-statistic: }{ }^{*} p<0.05,{ }^{* *} p<0.01,{ }^{* * *} p<0.001 \text {; Nagelkerke's } \mathrm{R}^{2}(\text { men })=0.25 \text {, Nagelkerke's } \mathrm{R}^{2} \text { (women) }=0.19 \text {, all } \\
\text { from final step; Hosmer-Lemeshow Goodness of Fit test (men): } \mathrm{x}^{2}=10.54, \mathrm{df}=8, \mathrm{p}=0.23 \text {; Hosmer-Lemeshow Goodness } \\
\text { of Fit test (women): } \mathrm{x}^{2}=11.90, \mathrm{df}=8, \mathrm{p}=0.16 \text {. }\end{array}$} \\
\hline
\end{tabular}

Table 2 Results from multivariate logistic hierarchical regression ( $2^{\text {nd }}$ step) predicting colonoscopy use ${ }^{1}$ among men and women aged 55 to 70 years ${ }^{2}$.
Data allowing the comparison of colonoscopy use between Germany and other European countries are very scarce. In France, where population-wide FOBT screening was stepwise introduced during the last few years only, a large survey conducted in 2006 reported a lifetime prevalence of colonoscopy use of 18\% (Institute for Research and Information in Health Economics, 2006) [12]. Even though interpretation of the latter is limited due to lack of information regarding the underlying age distri- bution, a lower lifetime prevalence of colonoscopy use in France compared to Germany would be highly plausible given the time gap in terms of introducing FOBT screening. In Austria, where population-wide CRC screening based on FOBT or lower endoscopy is recommended but cost coverage varies by region, about $25 \%$ of the population between $40-79$ years have undergone a colonoscopy according to a survey from 2005 [13]. Another European data source originating from Greece, where population- 
wide CRC screening has not been implemented, reported estimates on recent use of lower endoscopy (colonoscopy or sigmoidoscopy) of about $7-9 \%$ [14].

The comparison of data from the USA with the data from this German survey is encumbered for the following reason: while sigmoidoscopy is rarely done in Germany and not offered as a screening tool [4], it has been used for primary screening in the US for several years (as an alternative to FOBT screening). It has been shown that sigmoidoscopy cannot reliably be distinguished from colonoscopy by self-report [15]. U.S. health surveys therefore typically report the use of lower gastrointestinal endoscopy as a combined estimate for sigmoidoscopy and colonoscopy use. The National Health Interview Survey from 2000 reported lifetime prevalence of lower endoscopy use being $39 \%$ for respondents aged $\geq 50$ years [16], and $43 \%$ for respondents aged $\geq 65$ years [17]. The latter estimate rose to $48 \%$ in 2003 , i.e., two years after screening colonoscopy was covered by Medicare [17].

The above-mentioned data sources are generally not indicative of pronounced sex differences in prevalence of endoscopy use. However, slightly higher prevalences in men than in women are reported for some countries [6,18-20], while in Germany it seems to be vice versa. The higher proportion of women with previous colonoscopy in Germany may be attributed to the significant sex differences in adherence to FOBT screening, as reported previously [10]. However, the fact that the observed sex differences in colonoscopy use were small lends support to previous findings of a higher FOBT positivity rate in men compared with women leading to a higher number of follow-up colonoscopies in men than in women [21, 22]. Given that in Germany women tend to show higher adherence to screening colonoscopy than men, the sex difference regarding overall colonoscopy use could further increase in the long run [23].

As to other potential correlates, the marginal associations with socioeconomic variables indicate no or only very little social inequality in access to colonoscopy. This may reflect the health-care system in Germany where everyone has health insurance, whereas, for example, in the USA these variables have been shown to be important predictors of endoscopy use [24]. The reasons for sex-specific patterns of certain correlates would require further investigation.

The present study used a cross-sectional design limiting interpretation of the observed data in terms of age effects and causality of associations. Interpretation of our data is further limited by the fact that information on previous colonoscopy was based on self-reports only. However, validation studies from Germany and other countries verifying self-reported colonoscopies by comparison with medical records found that self-reported data on previous colonoscopy use are highly reliable [25-27]. We did not collect information on reasons for colonoscopy. Even though such information would be of interest, validity of self-reported data in terms of distinguishing between indications (diagnostic colonoscopy vs. screening colonoscopy) has been reported to be limited [25].

Specific strengths of our study pertain to the large sample, which was drawn using a method to arrive at samples representing the general population. Furthermore, we collected detailed information regarding potential correlates of colonoscopy use, including adherence to FOBT screening stratified by screening behaviour groups. We collected our data in 2004, when the screening colonoscopy programme, introduced in late 2002, had still a small impact on overall colonoscopy use. Our data thus provide a valuable point of reference regarding future developments, e.g., the long-term effect of screening colonoscopy or changes in the screening programme. The German CRC screening programme is currently opportunistic. Higher colonoscopy use would be expected when switching to an organised programme with invitations and reminders, which is a point of ongoing discussion. Furthermore, FOBT screening in Germany is currently based on the guaiac-based FOBT showing high specificity (and low sensitivity). An even higher prevalence of (diagnostic) colonoscopy use is to be expected if newer FOBTs with lower specificity (and higher sensitivity) were used for screening, e.g., certain immunochemical FOBTs [28], which would lead to a higher number of falsepositive test results being followed-up by colonoscopy.

In conclusion, our survey from 2004, when faecal occult blood testing (offered since more than 30 years) was still the most important CRC screening tool in Germany, suggests that more than one third of the population underwent colonoscopy at least once up to age 70 . While introduction of screening colonoscopy or further potential modifications of the screening programme (such as the introduction of an invitation system) are expected to impact on overall colonoscopy use in the long run, these data can serve as point of reference to assess the extent and the patterns of such changes.

\section{Acknowledgements}

$\nabla$

This research was funded by a grant from "Deutsche Krebshilfe" (German Cancer Aid) and by a grant from the Ministry of Science, Research and the Arts of Baden-Württemberg (Az: 24-729.18-1-13/4) to Monika Sieverding. The authors declare that they have no conflicts of interest.

\section{Appendix \\ $\nabla$}

Lifetime prevalence of colonoscopy use in 2004 (stratified by age and sex) for the scenario that screening colonoscopy, which has been introduced in late 2002, would not have been offered was estimated as follows.

First, the number of respondents in the respective age and sex group who had a previous colonoscopy which was not related to the screening colonoscopy programme was derived as follows and denoted $n($ everColadj) age,sex:

$\mathrm{n}(\text { everColadj })_{\text {age,sex }}=\mathrm{n}(\text { everCol })_{\text {age,sex }}-\mathrm{n}_{\text {age,sex }} \times \mathrm{C}(\text { ScreenCol })_{\text {age,sex, }}$ year1 $\times(1-$ PprevCol $)-\mathrm{n}_{\text {age,sex }} \times \mathrm{C}(\text { ScreenCol })_{\text {age,sex,year2 }} \times(1-$ PprevCol)

where

- $\mathrm{n}(\text { everCol })_{\text {age,sex }}$ is the number of respondents in the respective age and sex group who reported a previous colonoscpy in the survey,

- $\mathrm{n}_{\text {age,sex }}$ is the overall number of respondents in the respective age and sex group,

- $\mathrm{C}(\text { ScreenCol })_{\text {age,sex,year1 }}$ and $\mathrm{C}(\text { ScreenCol })_{\text {age,sex,year2 }}$ are the annual compliance rates with screening colonoscopy 2 years after its introduction (i.e., 2 years before the survey was conducted) in the respective age and sex group ( Table Appendix),

- PprevCol is the proportion of people who undergo screening colonscopy and had another colonoscopy before (i.e., screen- 


\begin{tabular}{|c|c|c|c|c|c|c|}
\hline \multirow{3}{*}{ year } & \multicolumn{3}{|l|}{ women } & \multicolumn{3}{|l|}{ men } \\
\hline & \multicolumn{6}{|c|}{ age group } \\
\hline & $55-59$ & $60-64$ & $65-70$ & $55-59$ & $60-64$ & $65-70$ \\
\hline 2003 & $3.5 \%$ & $4.1 \%$ & $3.1 \%$ & $2.2 \%$ & $3.0 \%$ & $2.7 \%$ \\
\hline 2004 & $4.4 \%$ & $5.0 \%$ & $3.8 \%$ & $3.0 \%$ & $4.0 \%$ & $3.5 \%$ \\
\hline
\end{tabular}

Table Appendix Compliance with screening colonoscopy stratified by age and sex in the two years after its introduction [7]; Percentages refer to the number of inhibitants in the respective age and sex group.

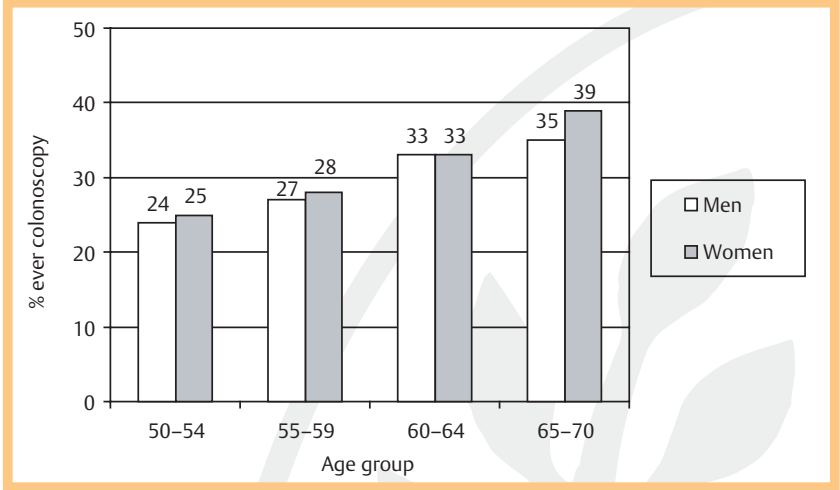

Fig. Appendix Estimated lifetime prevalence of colonoscopy use in 2004 for the scenario that screening colonoscopy would not have been offered, stratified by age and sex.

ing colonoscopy is not the first colonoscopy in life), which was estimated to be $28 \%$ [4].

The proportions for the respective age and sex group, denoted Prop(everColadj) age,sex, as displayed in the Fig. Appendix were then calculated as follows:

Prop $(\text { everColadj })_{\text {age,sex }}=n(\text { everColadj })_{\text {age,sex }} / n_{\text {age,sex }}$

\section{References}

1 Parkin DM, Bray F, Ferlay J et al. Global cancer statistics, 2002. CA Cancer J Clin 2005; 55: 74-108

2 Winawer SJ, Zauber AG, Ho MN et al. Prevention of colorectal cancer by colonoscopic polypectomy. The National Polyp Study Workgroup. Prevention of Colorectal Cancer by Colonoscopic Polypectomy. N Engl J Med 1993; 329: 1977-1981

3 Brenner H, Arndt V, Stürmer T et al. Long lasting reduction of risk of colorectal cancer following screening endoscopy. Brit J Cancer 2001; 85: 972-976

4 Brenner H, Chang-Claude J, Seiler CM et al. Does a negative screening colonoscopy ever need to be repeated? Gut 2006; 55: 1145-1150

5 Baxter NN, Goldwasser MA, Paszat LF et al. Association of colonoscopy and death from colorectal cancer: a population-based, case-control study. Ann Intern Med 2009; 150: 1-8

6 Stock C, Haug U, Brenner H. Population-based prevalence estimates of history of colonoscopy or sigmoidoscopy: review and analysis of recent trends. Gastrointest Endosc 2010; 71: 366-381

7 Brenner H, Hoffmeister M, Brenner $G$ et al. Expected reduction of colorectal cancer incidence within 8 years after introduction of the German screening colonoscopy program: estimates based on $1,875,708$ screening colonoscopies. Eur J Cancer 2009; 45: 2027-2033

8 Potthoff P, Heinemann LA, Güther B. Ein Haushalts-Panel als kosteneffektive Grundlage für bevölkerungsbezogene Gesundheitssurveys A household panel as a tool for cost-effective health-related population surveys: validity of the "Healthcare Access Panel". German Medical Science. 2004; 2, Doc 05: http://www.egms.de/pdf/gms/2004-2/ 000015.pdf accessed March 2nd, 2010

9 Federal Statistical Office. Statistical Yearbook for the Federal Republic of Germany: Statistisches Bundesamt (Federal Statistical Office) Wiesbaden; 2005
10 Sieverding M, Matterne U, Ciccarello L. Gender differences in FOBT use: evidence from a large German survey. Z Gastroenterol 2008; 46: S47S51

11 Wuppermann D, Wuppermann U, Riemann JF. [Actual state of knowledge of the german population about the early detection of colorectal cancer - a study by the "Stiftung LebensBlicke" in cooperation with the institute for demoscopy in Allensbach] [German]. Z Gastroenterol 2009; 47: 1132-1136

12 Institute for Research and Information in Health Economics (IRDES). The French Health, Health Care and Insurance survey 2006. http://www. irdes.fr/EspaceRecherche/Enquetes/ESPS/Dictionnaire2006/personne/ personne_coloscop.html [Accessed: March 2nd 2010]

13 Haidinger G, Waldhoer T, Vutuc C. Self-reported colonoscopy screening in Austria. Eur J Cancer Prev 2008; 17: 354-357

14 Kamposioras K, Mauri D, Golfinopoulos $V$ et al. Colorectal cancer screening coverage in Greece. PACMeR 02.01 study collaboration. Int J Colorectal Dis 2007; 22: 475-481

15 Vernon SW, Meissner H, Klabunde C et al. Measures for ascertaining use of colorectal cancer screening in behavioral, health services, and epidemiologic research. Cancer Epidemiol Biomarkers Prev 2004; 13 : 898-905

16 Subramanian S, Amonkar MM, Hunt TL. Use of colonoscopy for colorectal cancer screening: evidence from the 2000 National Health Interview Survey. Cancer Epidemiol Biomarkers Prev 2005; 14: 409-416

17 Shih YCT, Zhao L, Elting LS. Does Medicare coverage of colonoscopy reduce racial/ethnic disparities in cancer screening among the elderly? Health Affairs 2006; 25: 1153-1162

18 Wardle J, Miles A, Atkin W. Gender differences in utilization of colorectal cancer screening. J Med Screen 2005; 12: 20-27

19 Wee CC, McCarthy EP, Phillips RS. Factors associated with colon cancer screening: the role of patient factors and physician counseling. Preventive Medicine 2005; 41: 23-29

20 McQueen A, Vernon SW, Meissner HI et al. Are there gender differences in colorectal cancer test use prevalence and correlates? Cancer Epidemiol Biomarkers Prev 2006; 15: 782-791

21 U. K. Colorectal Cancer Screening Pilot Group. Results of the first round of a demonstration pilot of screening for colorectal cancer in the United Kingdom. BMJ 2004; 329: 133

22 Morikawa T, Kato J, Yamaji Y et al. Sensitivity of immunochemical fecal occult blood test to small colorectal adenomas. Am J Gastroenterol 2007; 102: 2259-2264

23 Knoepnadel J, Altenhofen L, Lichtner F et al. Frueherkennung des Darmkrebses und moeglicher Vorstufen - Wissenschaftliche Reihe des Zentralinstituts, Band 59 [Early detection of colorectal cancer and possible prestages]. Cologne: Deutscher Aerzte-Verlag, 2005

24 Shapiro JA, Seeff LC, Thompson TD et al. Colorectal Cancer Test Use from the 2005 National Health Interview Survey. Cancer Epidemiol Biomarkers Prev 2008; 17: 1623-1630

25 Hall HI, Van Den Eeden SK, Tolsma DD et al. Testing for prostate and colorectal cancer: comparison of self-report and medical record audit. Prev Med 2004; 39: 27-35

26 Baier M, Calonge N, Cutter G et al. Validity of self-reported colorectal cancer screening behavior. Cancer Epidemiol Biomarkers Prev 2000; 9: 229-232

27 Hoffmeister M, Chang-Claude J, Brenner H. Validity of self-reported endoscopies of the large bowel and implications for estimates of colorectal cancer risk. Am J Epidemiol 2007; 166: 130-136

28 Hundt S, Haug U, Brenner H. Comparative evaluation of immunochemical fecal occult blood tests for colorectal adenoma detection. Ann Intern Med 2009; 150: 162-169 